\title{
EDMUND HUSSERL: LOS OBJETOS COMO UNIDADES DE SENTIDO
}

\section{EDMUND HUSSERL: THE OBJECTS AS UNITS OF SENSE}

\author{
Franco César Puricelli ${ }^{1}$ \\ Universidad Nacional de Córdoba - CONICET (Argentina)
}

Recibido: 24-05-2018

Aceptado 30-08-2018

\begin{abstract}
Resumen: El presente trabajo se propone elucidar distintas aristas y consecuencias de la noción de objeto en la fenomenología de Husserl, tomando como referencia principal las lecciones de 1907, publicadas con el título: Ding und Raum (Cosa y Espacio). El trabajo busca dar cuenta del reconocimiento de la dimensión de sentido que dicha noción involucra, y de como la misma pretende distanciarse de las visiones clásicas, tanto realistas como idealistas. Para ello, se analizan las siguientes cuestiones: 1) el modo de darse (Gegebenheitsweise) del objeto a la percepción y el conocimiento, 2) la manera de entender los conceptos de identidad y trascendencia, 3) la manera de entender el vínculo objeto-propiedad.
\end{abstract}

Palabras-clave: Husserl, fenomenología, percepción, objeto, sentido.

\begin{abstract}
The aim of this work is to elucidate the different angles and consequences of the notion of object in Husserl's phenomenology (considering the 1907 lections Ding und Raum). This work tries to account for the recognition of the dimension of sense that is involved in that notion, and how it seeks to distance itself from such classic visions as realism and idealism. To accomplish this aim, the following matters are analyzed: 1) the mode of givenness (Gegebenheitsweise) of the object to perception and knowledge, 2) the way in which the concepts of identity and transcendence are understood, 3) the way in which the relationship between object and property is understood.
\end{abstract}

Keywords: Husserl, phenomenology, perception, object, sense.

1. Licenciado en Filosofía por la Universidad Nacional de Córdoba, Argentina. Doctorando en Filosofía por la misma universidad, con beca de CONICET, bajo la dirección de Alejandro G. Vigo y Ariela Battán Horenstein. (francopuricelli89@gmail.com) 


\section{Introducción}

Uno de los desarrollos más importantes de la filosofía de Edmund Husserl, a nuestro entender, es la consideración del objeto como unidad de sentido (Einheit des Sinnes). Este reconocimiento de la dimensión de sentido tiene una importante cantidad de aristas y consecuencias que trataremos de elucidar en el presente trabajo.

En un conocido y muy citado parágrafo de Ideas I, Husserl afirma: «En cierta forma y con alguna cautela puede decirse también: "todas las unidades reales en sentido estricto son unidades de sentido". ${ }^{2}$ Ahora bien, ¿qué quiere decir esto? ¿Quiere decir acaso que hay cierto elemento de subjetividad o de arbitrariedad en la determinación de las unidades objetivas? ¿Quiere decir que el mundo es una especie de construcción de la conciencia? Es importante detenerse a analizar este planteo con detalle, ya que con él Husserl pretende distanciarse tanto del realismo de sentido común, que no problematiza la dimensión interpretativa de la experiencia, como del idealismo radical, que reduce el mundo a sensaciones e ideas.

La consideración del objeto como unidad de sentido tiene varios elementos e implica distintos niveles de estudio. El objetivo de este trabajo es recorrer dichos elementos y niveles, con el propósito de entender mejor su significado concreto e intereses generales. Consideramos que es necesario analizar las nociones que aquí presentamos en sus distintas aristas y relaciones mutuas, evitando confusiones o malentendidos, ya que no se trata de una tesis aislada, sino de un conjunto de abordajes que involucran el análisis de la percepción, del conocimiento y hasta del lenguaje. La noción de objeto nos servirá tanto de punto de partida como de centro organizador de varios abordajes husserlianos que, a nuestro entender, son de profunda relevancia filosófica.

Tomaremos como referencia, fundamentalmente, las lecciones de 1907, publicadas bajo el título Ding und Raum (Cosa y Espacio). La elección del texto obedece a varias razones: 1) las lecciones están dedicadas en buena parte al estudio de la noción de objeto; 2) existen pocos comentarios y análisis sobre las mismas ${ }^{3}$; 3) se encuentran situadas históricamente entre la publicación de dos obras clásicas de Husserl: Investigaciones Lógicas (1900-1901) e Ideas I (1913).

En Ding und Raum, Husserl no plantea todavía muchas de las tesis fundamentales que luego serán desarrolladas en Ideas I. Principalmente, no nos encontramos aún con la distinción entre noesis y noema, así

2. Edmund Husserl, Ideas, FCE, México DF, 1962, Libro Primero, §55.

3. Dentro de la bibliografía citada en este trabajo, los textos de Walter Hopp y Kevin Mulligan hacen referencia explícita a Ding und Raum.

Thémata. Revista de Filosofía $\mathrm{N}^{\circ} 58$ (2018) pp.: 35-48. 
como con el consiguiente análisis pormenorizado de las estructuras noético-noemáticas. ${ }^{4}$ Sin embargo, en lo que respecta al reconocimiento de la dimensión de sentido en el objeto, el autor ya ha dado -en las lecciones de 1907 como también en las Investigaciones Lógicas- pasos verdaderamente significativos. Por eso, creemos que hay buenos motivos, tanto históricos como filosóficos, para servirnos del mencionado texto en el análisis de una serie de tópicos centrales en la obra de Husserl.

La consideración del objeto remite, en primer lugar, al modo de darse (Gegebenheitsweise) del mismo a la conciencia, y con esto, a la manera en que este darse implica siempre un acto de aprehensión interpretativa (Auffassung $)^{5}$ de contenidos de sensación. En segundo lugar, nos obliga a ampliar la mirada más allá del simple objeto como individuo o sustancia, y considerar elementos tales como el horizonte en que se presenta y la dirección de interés que guía el acto intencional que lo aprehende. En tercer lugar, exige una reformulación de la manera en que es concebida tanto la identidad del objeto como su trascendencia. Por último, implica un ambicioso intento de reinterpretar el vínculo entre el objeto y sus propiedades y relaciones.

\section{La aprehensión}

La dimensión de sentido en el objeto es reconocida por Husserl, en primer término, cuando afirma que el mismo no se da a la conciencia a partir de una mera acumulación de sensaciones, sino que exige además un acto de aprehensión interpretativa (Auffassung). El objeto así constituido es precisamente una unidad de sentido que se mantiene en el cambio de las sensaciones. Lo que percibimos - por ejemplo, un árbol- se encuentra alternativamente más cerca o más lejos, se modifican las condiciones de luz que nos permiten verlo, se modifica también el punto de vista desde el cual lo miramos. Todo esto implica un cambio en las sensaciones que nos presentan ese objeto, pero eso no impide que nuestra conciencia lo aprehenda como "el mismo árbol" que es. La dinámica de la aprehensión objetiva no se ve obstaculizada por el cambio de las sensaciones, más bien lo contrario, lo exige. Esto es así porque el objeto no se conoce a partir de

\footnotetext{
4. Cf. Ibídem, Sección Tercera.

5. Traducimos Auffassung como aprehensión interpretativa (a veces simplemente aprehensión o aprehensión objetiva). Para Husserl, la Auffassung implica, por así decir, tanto captación como interpretación.
} 
una imagen rígida del mismo, sino a partir del desenvolvimiento dinámico de nuestro trato con él.

Pertenece a la esencia del ser-cosa en general el ser una unidad intencional idéntica, que se "constituye" en una determinada colección de apariencias -efectivas o posibles- y que se identifica, tanto en su ser como en su correspondiente ser-así, en un entramado de apariencias ordenadas y en cada caso motivadas. Pero este entramado es un entramado de apariencias armónicas, que se completan mutuamente y que son asumidas por una conciencia de creencia continua, o mejor dicho, por una conciencia positiva de ser [Setzungs- Seinsbewußtsein $]{ }^{6}$

Esta definición expresa varios elementos centrales de la manera husserliana de concebir el objeto. En primer lugar, la definición del objeto remite al modo de darse (Gegebenheitsweise) del mismo en un acto de conciencia. El objeto es una unidad intencional que se presenta en un entramado de sensaciones, pero que no se reduce a él, desde el momento en que mantiene su identidad, aunque las sensaciones se modifiquen. Más aún, los aspectos del objeto no dados ahora efectivamente -aprehendidos en forma impropia, sin las sensaciones correspondientes- forman parte también de su unidad.

No se trata de que el objeto sea construido o elaborado por el sujeto. La afirmación de que la conciencia pone orden y estructura en el caos de las apariencias puede generar confusiones y malentendidos. La conciencia, más bien, constituye un sentido allí donde en principio sólo hay sensaciones. Por eso mismo, además de los contenidos de sensación, la percepción exige un plus que Husserl denomina aprehensión.

Los contenidos de sensación no contienen por sí mismos todavía el carácter de la percepción, no contienen nada de la dirección a un objeto percibido; no son todavía aquello que hace que algo objetivo esté ahí en carne propia. Llamamos a este plus el carácter de aprehensión y decimos que los contenidos de sensación experimentan aprehensión. Estos contenidos -que por sí mismos serían materia muerta- obtienen, mediante la aprehensión, una significación viva, en el sentido de que con ellos viene a presentarse un objeto. ${ }^{7}$

Cuando hablamos de sensación nos referimos a los contenidos que son vividos por la conciencia como inmanentes. En cambio, los objetos y sus cualidades objetivas pertenecen al entramado del mundo, al ámbito de lo que trasciende la conciencia. Las sensaciones, para Husserl, presentan las cualidades del objeto, pero no se identifican con ellas. No tiene sentido, por ejemplo, decir que el verde del árbol es una sensación de verde o que la sensación de verde pueda ocupar un lugar en el espacio. Un objeto no

6. Edmund Husserl, Ding und Raum (Husserliana XVI), M. Nijhoff, La Haya, 1973, §84, primer párrafo. (La traducción es nuestra)

7. Ibídem, §15, primer párrafo. (La traducción es nuestra)

Thémata. Revista de Filosofía $\mathrm{N}^{\circ} 58$ (2018) pp.: 35-48. 
puede en ningún caso estar dentro de la conciencia como un contenido de la misma, del mismo modo que un amontonamiento de sensaciones jamás puede constituir por sí mismo un objeto del mundo. ${ }^{8}$

Es importante mencionar que la consideración del modo de darse nos muestra que, en la percepción, el objeto se da siempre "por un lado", esto es, de manera incompleta y a partir de ciertas determinaciones. No es posible tener a la vista, por ejemplo, todos los lados de un objeto al mismo tiempo. Husserl da cuenta de esto diciendo que forma parte de la naturaleza del objeto el no poder ser percibido sino a través de escorzos (Abschattungen). Lo que llamamos percepción de cosas en general consta por tanto de aprehensiones propias e impropias, de lados o momentos que son presentados por contenidos de sensación y otros que son co-aprehendidos como aquello que también está ahí, aunque no propiamente presente.

Lo percibido propiamente, en base a contenidos de sensación presentes, demanda el complemento de las aprehensiones impropias. Si no existiera este entrelazamiento de aprehensiones propias e impropias, jamás podríamos tener frente a nosotros un objeto, ni siquiera un lado del mismo, puesto que los lados no son algo autónomo ni separable. Sin el objeto, el lado no es tal. Las sensaciones, en cambio, no responden a esta estructura de presentaciones "por un lado". La sensación se da siempre como lo que es en forma completa, sin lados ni perspectivas posibles. La sensación no tiene un reverso. ${ }^{9}$

Un mismo objeto es percibido en base a contenidos de sensación cambiantes, desde diferentes puntos de vista, en condiciones de visibilidad que varían también. Existe, no obstante, una conciencia de identidad que dispone estos contenidos diversos en la unidad de un mismo objeto. ${ }^{10}$ Este importante hallazgo husserliano señala la necesidad de estudiar los actos de la conciencia a la hora de dar cuenta del fenómeno mismo de la objetividad. El estudio de los objetos en general remite desde un principio al estudio de la unidad de los actos constituyentes de la conciencia, los actos de identificación y distinción. En palabras del propio Husserl, «la cosa se

8. Como es sabido, Husserl plantea esta distinción ya en las Investigaciones Lógicas, fundamentalmente en la Investigación Quinta, en la cual el análisis de las vivencias perceptivas tiene un rol esencial. En Ding und Raum, el análisis se realiza en forma más pormenorizada y ejemplificada, pero no hay, en lo que respecta a esta distinción, un cambio de postura por parte del autor. (Cf. Edmund Husserl, Investigaciones lógicas, Alianza, Madrid, 2006, Tomo II, Inv. V, §14.)

9. Cf. Edmund Husserl, Ding und Raum (Husserliana XVI), Nijhoff, La Haya, 1973, §14-18. 10. Cf. Ibídem, $\S 10$.

Thémata. Revista de Filosofía $\mathrm{N}^{\circ} 58$ (2018) pp.: 35-48. 
constituye en la conciencia, es una intencionalidad (...) lo que le da sentido a ésta y a su ser-verdad.» ${ }^{11}$

Este reconocimiento de la dimensión de sentido en el objeto no debe interpretarse como implicando algún tipo de arbitrariedad en la aprehensión. Aquí no quiere decirse que el objeto sea el resultado de una pura elaboración subjetiva, por el contrario, la aprehensión se da siempre siguiendo reglas determinadas en función de los complejos de sensaciones que son considerados en cada caso. ${ }^{12}$ La actividad de la conciencia no crea el mundo de la nada, sino que brinda el elemento de sentido a una experiencia que de lo contrario sería incapaz de establecer continuidades objetivas en el flujo de sensaciones. Es necesario, por tanto, un idealismo que establezca el rol de la conciencia en la constitución de las objetividades sin reducirlas a sensaciones o ideas, y un realismo que establezca la trascendencia de las cosas sin desconocer el rol de la aprehensión interpretativa. Esto es lo que se propone la noción husserliana de objeto, y su valor se encuentra en haberlo intentado de una manera al mismo tiempo profunda y pormenorizada.

\section{Los contenidos de sensación}

Es necesario profundizar ahora en algunos elementos planteados en el apartado anterior, relativos a la diferencia entre los contenidos de sensación y los objetos del mundo. La distinción se desarrolla a partir del análisis del modo de darse (Gegebenheitsweise) de ambos: es una distinción entre lo que la conciencia vive íntimamente en forma completa y lo que se le presenta en tal o cual sentido, siempre en escorzos, siempre dejando lugar a una indagación ulterior. La teoría husserliana de la percepción conserva esta doble dirección en todo momento: por un lado, hacia los contenidos de sensación, y por otro, hacia los objetos del mundo. La percepción, al mismo tiempo que presenta los objetos del mundo, interpreta las sensaciones.

Esto ha generado confusiones y críticas en distintos lectores e intérpretes de Husserl. ${ }^{13}$ ¿Cómo se explica la dirección al objeto del acto perceptivo, si por otro lado parece posible dar cuenta de la percepción atendiendo únicamente al plano de la conciencia, a los contenidos de sensación y la aprehensión interpretativa de los mismos? ¿Cuál es la función de las

11. Ibídem, §13, párrafo seis. (La traducción es nuestra)

12. Cf. Ibídem, §84.

13. Para una reconstrucción de la teoría de la percepción de Husserl, así como de algunas de las críticas que se le han hecho: cf. Walter Hopp, "Husserl on Sensation, Perception and Interpretation" en Canadian Journal of Philosophy, 2008, Vol. 8, Nro. 2.

Thémata. Revista de Filosofía №58 (2018) pp.: 35-48. 
sensaciones si en sí mismas no tienen contenido representativo alguno? El propio Husserl ha insistido en el rechazo a la idea de que las sensaciones pudieran ser una especie de imagen interna que representa un objeto exterior. Él afirma que la percepción capta los objetos del mundo y no alguna representación de ellos. ¿En qué radica entonces la importancia de los contenidos de sensación?

Recordaremos cuatro rasgos fundamentales de la sensación: 1) En primer lugar, como dijimos, las sensaciones no son objetos de percepción, son vividas por la conciencia, pero no percibidas por ella originariamente. 2) A diferencia del objeto del acto perceptivo, las sensaciones son componentes reales de la conciencia. 3) A pesar de que las sensaciones no son representaciones o imágenes internas de los objetos, existe no obstante algún tipo de semejanza entre las propiedades objetivas y las sensaciones que las presentan. De hecho, una sensación auditiva no puede presentar jamás una propiedad visual. 4) Los contenidos de sensación no son en sí mismos intencionales. Adquieren esta función únicamente cuando son aprehendidos por la conciencia. ${ }^{14}$

Si bien Husserl pretendía que la incorporación de los contenidos de sensación facilitaría el acercamiento entre la conciencia y el mundo, para los críticos de dicho enfoque en realidad no ha hecho más que interponer una suerte de híbrido que, en sentido estricto, no puede ser parte del mundo ni de la conciencia. ${ }^{15}$ Además, la manera en que se supone que la sensación cumple un rol en la presentación del objeto a la conciencia no deja de tener ciertas oscuridades. La idea de una semejanza entre la sensación y la propiedad objetiva no hace más que complicar la situación, ya que parece implicar algún resabio de la idea de que percibimos imágenes o representaciones de las cosas, y esto es precisamente lo que Husserl más ha intentado poner en discusión.

Ahora bien, ¿es posible dejar de lado los contenidos de sensación sin ninguna pérdida en la descripción fenomenológica de la relación entre la conciencia y el mundo? Esto no parece sencillo de aceptar, puesto que los mismos cumplen al menos dos funciones esenciales que Husserl menciona en reiteradas oportunidades. En primer lugar, dan cuenta del hecho de que no siempre un cambio en las sensaciones implica un cambio en la aprehensión objetiva. Si eliminamos los contenidos de sensación, parece que estamos obligados a decir que todas las percepciones de un mismo objeto son idénticas desde todo punto de vista. En segundo lugar, los contenidos marcan la diferencia entre la aprehensión propia y la impropia. Esta diferencia es fundamental a la hora de concebir el proceso de conocimiento y

14. Cf. Walter Hopp, obra citada, págs. 229 y 230.

15. Cf. Ibídem, págs. 230 y 231.

Thémata. Revista de Filosofía $\mathrm{N}^{\circ} 58$ (2018) pp.: 35-48. 
la posibilidad de sumar nuevas determinaciones a medida que cambiamos de enfoque o de perspectiva. ¿Cómo diferenciamos si no la aprehensión que tenemos de la cara "presente" de un objeto de la aprehensión que tenemos de las demás?

Si bien no pretendemos dar por cerrado el debate sobre los contenidos de sensación en este apartado, haremos no obstante una breve reflexión final. Las objeciones a la postulación de dichos contenidos parecen estar dando por hecho un esquema de interioridades y exterioridades que podríamos interpretar que el propio Husserl no asume en ningún momento. De hecho, si suponemos que los contenidos de sensación están en la interioridad de la conciencia y que además la aprehensión interpretativa de los mismos también es un hecho interno, entonces jamás podremos dar el salto a la exterioridad del objeto. Esto también nos llevaría a pensar en los contenidos como imágenes internas de las cosas externas. Pero si tratamos de seguir lo que de hecho afirma Husserl y concedemos que verdaderamente pretende alejarse de las mencionadas maneras tradicionales de abordar el tema -a pesar de que ciertas expresiones puedan favorecer la confusión-, tal vez podamos analizar su teoría bajo una luz nueva. Si conceptos tales como sensación, aprehensión, sentido, conciencia y objeto no pretenden trazar una línea divisoria entre ámbitos interiores y exteriores, sino más bien determinar elementos que componen la complejidad de un único ámbito de la experiencia, resulta probable que las objeciones adjudiquen a la teoría de Husserl un problema que en verdad no tiene sentido dentro de la visión general que la misma propone.

\section{Movimiento y horizonte}

En este apartado analizaremos otros aspectos esenciales del modo de darse de los objetos. En primer lugar, es importante señalar que la cosa percibida nunca se encuentra aislada ni se da a nuestra consideración como un puro individuo, desconectado de cualquier tipo de relación. La cosa percibida, sin dejar de ser una unidad diferenciada, aparece siempre en medio de un entorno de cosas (Dingumgebung). Este entorno, si bien no atendido específicamente, es también percibido. No es posible, sin mediar algún tipo de abstracción, separar la percepción de entes individuales de esta mirada amplia y compleja de un escenario de objetos dispuestos de tal o cual manera. ${ }^{16}$

Este entorno de cosas co-percibidas incluye también al Yo-cuerpo (Ichleib), el cual se encuentra allí como cuerpo objetivo y además ocupando un lugar preeminente como referencia, en la medida en que aporta un de-

16. Cf. Edmund Husserl, Ding und Raum (Husserliana XVI), M. Nijhoff, La Haya, 1973, §24.

Thémata. Revista de Filosofía $\mathrm{N}^{\circ} 58$ (2018) pp.: 35-48. 
terminado punto de vista (Standpunkt), un "desde dónde" de la percepción y de los comportamientos en general. Ahora bien, ni la cosa percibida ni el Yo-cuerpo son elementos estáticos, sino que el movimiento es uno de sus rasgos esenciales. El punto de vista va cambiando, el objeto se mueve, el entorno mismo se modifica. Percibir objetos es ser consciente de las identidades que se mantienen a lo largo de los cambios, tanto en el plano de la sensibilidad como en el plano de la disposición objetiva de las cosas.

Cuando se asume esta perspectiva dinámica del fenómeno de la percepción, el cambio en los contenidos de sensación vividos no resulta un impedimento para dar cuenta de la identidad del objeto, sino que se vuelve una necesidad. A medida que nos acercamos a un objeto inmóvil, por ejemplo, es esperable que las sensaciones que presentan dicho objeto se vayan modificando. Además, todo objeto se conforma esencialmente de múltiples lados, pero se presenta solamente por uno de ellos, de manera tal que siempre hay una disposición de lados visibles y no visibles que se va modificando. Todo escenario de percepciones actuales implica otros escenarios de percepciones posibles que se suceden en forma coherente y en consonancia con el movimiento y el cambio.

Es justamente en la aprehensión donde se constituyen las relaciones entre los diversos continuos de sensaciones, así como entre lo dado propiamente a partir de sensaciones y lo co-dado impropiamente. ${ }^{17}$ Sin esta conexión entre sensaciones de distinto tipo (visuales, táctiles, etc.) y sin la conexión entre los lados visibles y los no visibles, sería imposible tener noción de objeto alguno. El estar-ahí del objeto se constituye a partir de este múltiple darse a la percepción en escorzos que, como tales, son siempre escorzos de algo, momentos de una unidad que los contiene. El objeto, entonces, es lo que es sólo en tanto polo que unifica y sistematiza tales escorzos y posibilidades de escorzos. ${ }^{18}$

Para dar cuenta del sentido concreto de un objeto, es necesario siempre ir más allá del mismo entendido como algo aislado. Todo objeto singular percibido lleva consigo su horizonte de otras percepciones posibles. Dicho horizonte se extiende tanto espacial como temporalmente, de modo tal que cada objeto remite a un mundo que lo circunda, así como también a un pasado y un futuro. Nuestro trato con las cosas, por tanto, se desenvuelve siempre en tales horizontes, y referirnos a un objeto individual implica en cada caso poner en juego ese conjunto de relaciones. Esto no quiere decir que la experiencia se desarrolle siempre en armonía, sino

17. Cf. Ibídem, $\S 22$.

18. Cf. Ibídem, §29-30.

Thémata. Revista de Filosofía $\mathrm{N}^{\circ} 58$ (2018) pp.: 35-48. 
más bien que las tensiones propias de la misma presuponen una base no conflictiva. ${ }^{19}$

\section{Dirección de interés}

Las nociones que venimos presentando suscitan, por distintas razones, especulaciones sobre la naturaleza del conocimiento. A propósito de este tema, encontramos en el texto de Ding und Raum (Cosa y Espacio) algunas reflexiones que nos parecen de gran interés.

Como consecuencia de lo dicho hasta aquí, Husserl sostiene que un objeto no puede darse nunca por completo a la percepción, que en nuestro conocimiento perceptivo resta esencialmente un fondo de inadecuación. Todo proceso de percepción implica un enriquecimiento y determinación más precisa de la manera en que se dan ciertas cosas y momentos de cosas, y simultáneamente un empobrecimiento de la manera en que se dan otras cosas y momentos de cosas. Es imposible aprehender propiamente todos los lados y momentos de un objeto a la vez: aquí reside la inadecuación esencial de toda percepción de cosas del mundo. Esto quiere decir que un objeto nunca puede darse en forma absoluta a nuestra consideración, siempre hay elementos faltantes, siempre hay áreas de indeterminación e impropiedad. ${ }^{20}$

Ahora bien, ¿qué podemos conocer entonces? ¿Es posible que nuestras pretensiones de conocimiento -al menos en relación con un caso concreto- puedan darse por satisfechas alguna vez? En la medida en que conocer no es simplemente tener una imagen de la cosa, sino también tener conciencia de ella como formando parte de un entorno en el cual adopta ciertas disposiciones y desenvolvimientos, no es posible conocer a través de un contacto inmediato y privilegiado. El conocimiento exige una sucesión de experiencias, un proceso de determinación y redeterminación que Husserl considera infinito, ya que no es concebible un caso en que hayamos dado cuenta de todos los momentos y determinaciones de algo en forma definitiva. Husserl llega a afirmar que «no estamos en condiciones de señalar como una meta razonable el determinar una cosa cualquiera en forma absoluta.» ${ }^{21}$ Tal es así que, si pretendemos dar cuenta del conocimiento como una tarea que se encamina por medios razonables hacia objetivos razonables, es necesario que modifiquemos en aspectos esenciales nuestra visión general respecto del mismo. La pregunta por la determinación absoluta de

19. Cf. Ludwig Landgrebe, El camino de la fenomenología, Sudamericana, Buenos Aires, 1968, pág. 67.

20. Cf. Edmund Husserl, Ding und Raum (Husserliana XVI), M. Nijhoff, La Haya, 1973, §33.

21. Ibídem, §38, segundo párrafo. (La traducción es nuestra)

Thémata. Revista de Filosofía №58 (2018) pp.: 35-48. 
la cosa en sí, tan cara al pensamiento metafísico, debe ser dejada a un lado para dar lugar a nuevas perspectivas de estudio.

Es esto lo que pretende hacer Husserl en el parágrafo 36 de Cosa y Espacio cuando sostiene que toda aprehensión de un objeto -ya sea propia o impropia- está guiada por una "dirección de interés". ¿Qué quiere decir esto? Fundamentalmente, que nunca tomamos en consideración un objeto en sí mismo sino mediante algún tipo de pregunta o interés previos. «La perspectiva óptima o normal de una cosa varía con los intereses del sujeto.» ${ }^{22}$ El ejemplo mencionado por Husserl y citado en varios estudios es el que dice que el interés espontáneo de quien observa una flor no es el mismo que el interés del botánico. La dirección de interés determina nada menos que las cualidades a tener en cuenta en cada caso, determina qué cambios en los contenidos de sensación o en las cualidades objetivas son relevantes y cuáles no. Si el interés cambia, una variación que antes resultaba insignificante puede tomar ahora el centro de la escena.

Cada percepción de cosas tiene su mención, la cual determina como qué vale [gelten], por así decir, el objeto aprehendido, qué se pretende, por así decir, con la percepción, y así también el sentido de su posible cumplimiento [Erfüllung]. ${ }^{23}$

No podemos tener un conocimiento absoluto y definitivo de un objeto, sino que siempre tenemos noticia de él a través de algunas de sus determinaciones y momentos. Ahora bien, el conocimiento de dichas determinaciones y momentos -por muy acabado que sea- se encuentra en la situación paradójica de que tales elementos no resultan separables del objeto al que pertenecen y que por lo tanto no son nada en sí mismos. La respuesta de Husserl a esta problemática es que, si bien el conocimiento de las determinaciones y momentos no vale como conocimiento de algo en sí ni tampoco como conocimiento acabado del objeto, vale en cambio como respuesta satisfactoria a una determinada dirección de interés en relación con el objeto. Es por eso que los criterios que definen cuándo se ha dado algo en forma satisfactoria y cuándo se ha enriquecido o empobrecido el grado de determinación de lo aprehendido, no dependen solamente del ob-

22. Kevin Mulligan, "Perception" en Cambridge Companion to Husserl, 1995, pág. 204. (La traducción es nuestra)

23. Edmund Husserl, Ding und Raum (Husserliana XVI), M. Nijhoff, La Haya, 1973, §37, segundo párrafo. (La traducción es nuestra)

Thémata. Revista de Filosofía $\mathrm{N}^{\circ} 58$ (2018) pp.: 35-48. 
jeto aprehendido y de las sensaciones que lo presentan, sino de la dirección de interés que define la orientación y criterio del acto perceptivo.

\section{Identidad y trascendencia}

La consideración del objeto como unidad de sentido conlleva una reformulación de la manera en que se concibe el continuo "ser lo que es" de cada cosa (identidad), así como su ser distinto de la conciencia que lo toma en consideración (trascendencia). Como veremos, lo que se intenta es dejar a un lado la manera metafísica de definir tales nociones -la cual se basa fundamentalmente en la idea de que identidad y trascendencia son conceptos absolutos-, para pasar a una visión que los define a partir de un conjunto de relaciones y de tensiones entre elementos distinguibles.

En efecto, hemos visto que son varios los elementos que determinan la identidad del objeto. En primer lugar, hay un acto de aprehensión a partir del cual se da una unidad de sentido que permanece en el cambio de sensaciones. En segundo lugar, hay un entorno de cosas co-aprehendidas que también forma parte del sentido concreto de cada cosa que se da a nuestra consideración. Estos dos elementos mencionados dan al objeto y a la percepción un carácter dinámico. En tercer lugar, hay una dirección de interés que acaba brindando el marco para definir el darse adecuado o inadecuado de una cosa.

Lo que se quiere decir, con todo esto, es que para poder dar algún tipo de definición de la identidad de un objeto, es necesario estar en condiciones de establecer un esquema de propiedades esenciales y accidentales, de propiedades que comprometen íntimamente dicha identidad y propiedades que no lo hacen. Esto no puede hacerse a partir de la mera consideración material del objeto, por mucho que esto parezca viable al sentido común. El punto de vista material desvirtúa cualquier concepto de identidad, ya que materialmente los cambios no están dimensionados ni jerarquizados -una partícula más en una bola de nieve altera la identidad de ésta-. Tampoco vale el procedimiento metafísico, el cual determina $a$ priori y de manera universal las sustancias y sus propiedades esenciales. Este procedimiento establece las identidades "por definición" y es por tanto en buena medida tautológico, unilateral y desentendido de todo contexto empírico. ${ }^{24}$ De más está decir, por último, que la identidad no puede determinarse en el nivel de las sensaciones. Como vimos, las propiedades objetivas no se constituyen a partir de la simple sucesión de sensaciones, sino

24. El ejemplo por excelencia del procedimiento metafísico es la definición cartesiana de la sustancia pensante y la sustancia extensa.

Thémata. Revista de Filosofía №58 (2018) pp.: 35-48. 
más bien a partir de la aprehensión interpretativa. Por eso los cúmulos de sensaciones no conforman de por sí objetos.

El objeto, entonces, alberga en sí mismo necesariamente momentos de tensión y de contradicción, está siempre abierto a correcciones y redeterminaciones. Nunca se da en forma completa, y no por razones circunstanciales, sino porque su propia naturaleza implica ese modo de darse. Cada objeto es una profundidad inagotable, y es en el transitar esas profundidades donde se definen los rasgos de nuestra realidad, del mundo en que vivimos. No hay caracteres inmediatos que distingan la vigilia del sueño, la percepción de la ilusión, la sabiduría de la superstición. Solamente es posible definir estos fenómenos en el trato con las cosas, en el movimiento, en la consideración continua de anversos y reversos.

Esto nos conduce a la cuestión de la trascendencia del objeto, de su ser distinto de la conciencia. Aquí Husserl parte del rechazo de la distinción entre las cosas "en sí" y las cosas "para nosotros", la cual había sido defendida, entre otros, por su maestro Franz Brentano. ${ }^{25}$ Según dicha distinción, la conciencia nunca se dirige al objeto sino a nuestras representaciones sobre el objeto, nuestra conciencia no tiene contacto con la realidad, está encerrada en sus propias imágenes y pensamientos. De este modo, hay siempre un abismo entre el ser de las cosas y el conocimiento de las mismas.

Husserl, en cambio, define el ser del objeto según su modo de darse (Gegebenheitsweise) y no deja lugar, por tanto, a distinciones entre la cosa "en sí" y la cosa "para nosotros". Que el objeto sea trascendente a la conciencia, que no sea un elemento de la corriente de las vivencias, se determina por el hecho de que nunca se da a la conciencia en forma completa. Siempre hay aspectos desconocidos y vaguedades. La conciencia no tiene, por tanto, jamás una imagen completa del objeto. En lugar de inferir una realidad "en sí" a partir de una realidad "para nosotros", la fenomenología estudia el modo en que se legitiman, en el mismo plano de la experiencia, nuestras afirmaciones de efectividad. Las diferencias entre la afirmación cierta y la falsa, entre la percepción correcta y la incorrecta no se establecen apelando a otro nivel más allá de la experiencia.

Según Roman Ingarden, la concepción husserliana del objeto está errada en su orientación inicial, en su pretensión de caracterizar el objeto a partir de su modo de darse. En efecto, sostiene que un objeto puede darse inadecuadamente, nuestro saber sobre él puede contener indeterminaciones y vaguedades, pero no puede ser en sí mismo indeterminado. Lo que

25. Para la reconstrucción de las diferencias entre los enfoques de Brentano, Husserl e Ingarden, nos servimos del texto de Roberto Walton: "Fenomenología y Realidad" en Escritos de Filosofía, Buenos Aires, 1985, Nro. 15-16.

Thémata. Revista de Filosofía $\mathrm{N}^{\circ} 58$ (2018) pp.: 35-48. 
él denomina el "objeto autónomo" está en todo caso unívoca y plenamente determinado. Lo contrario, según Ingarden, sería afirmar que el mundo es siempre idéntico a nuestro conocimiento. La indeterminación del objeto aprehendido se funda, de hecho, en la determinación del objeto en sí y sólo es posible por ella. Si la unidad de sentido aprehendida agotara el ser del objeto, no podría concebirse ningún tipo de inadecuación. El objeto como correlato de la vivencia es una presentación inadecuada de algo más, no puede ser en sí mismo una presentación inadecuada.

La teoría de Husserl no permitiría entonces diferenciar entre las alteraciones de sentido y las alteraciones reales. Cuando decimos que algo cambió de color, no decimos que cambió nuestra aprehensión del objeto, sino el objeto en sí. En cambio, muchas veces cambia nuestra aprehensión sin que se modifique en nada el objeto, como cuando decimos que un objeto parecía de lejos una cosa y terminó siendo otra distinta. La caracterización husserliana del objeto no daría cuenta de estos puntos fundamentales. Ingarden se pregunta, pues, si tiene sentido definir distintos modos de ser a partir de distintos modos de darse. ${ }^{26}$

Ahora bien, si la manera correcta de definir modos de ser no es la consideración de los modos de darse, ¿qué otro método puede utilizarse para esta tarea sin resignar solidez y rigor analítico? Siempre se puede asumir la existencia de un objeto "en sí" más allá de las unidades de sentido indeterminadas, pero ¿cómo puede fundamentarse una aseveración de este tipo, más aún cuando ya se ha dado por hecho que sólo conocemos directamente los objetos tal como se dan y no tal como son? La postulación de un objeto "en sí" siempre acaba en el mismo problema: si se encuentra más allá de la experiencia, ¿qué podemos decir sobre él? La distinción metafísica entre la cosa "en sí" y la cosa "para nosotros" no puede concluir más que la imposibilidad del conocimiento, ya que nos fuerza a concebirnos como encerrados en representaciones que pueden o no corresponderse con la realidad "exterior".

La teoría husserliana, en cambio, no se ocupa de un supuesto fundamento de la experiencia, ubicado en algún lugar más allá de la misma, inaccesible a la consideración directa. Su labor se centra en el estudio de las vivencias intencionales y sus correlatos, así como de las leyes y caracteres esenciales que rigen su ser y su desenvolvimiento. Por otra parte, podemos decir que las críticas de Ingarden no tienen debidamente en cuenta los análisis y aclaraciones del propio Husserl. Cuando analizábamos la importancia del movimiento en la descripción de las vivencias perceptivas, dijimos ya que la consideración del propio movimiento era fundamental para diferenciar cambios en el objeto de simples cambios de

26. Cf. Roberto Walton, obra citada, págs. 211 a 214. 
enfoque. Las nuevas aprehensiones nos acercan aspectos que no conocíamos o corrigen aprehensiones anteriores, pero no modifican el objeto. Ingarden asume que caracterizar el objeto como unidad de sentido es lo mismo que afirmar que cada cosa es idéntica a la representación actual que se tiene de ella. Esto supondría un sujeto de lo más ingenuo, incapaz de ir siquiera un poco más allá de sí. Semejante manera de ver las cosas no se parece en nada a la que hemos estado describiendo y analizando hasta recién como propia de la fenomenología husserliana. La diferencia más importante es que, para Husserl, la inadecuación del darse no se funda en la existencia de un objeto en sí inaprehensible en forma directa, sino en la propia estructura de la experiencia, la cual se basa en la constante corrección y profundización. Si la experiencia nos acerca unidades de sentido indeterminadas y conflictivas, ¿por qué suponer cosas en sí unívoca y plenamente determinadas? El pensamiento nunca agota del todo el ser de la cosa, pero no porque exista algo más allá, sino porque la cosa misma se presenta como algo abierto e incompleto.

\section{El vínculo objeto-propiedades ${ }^{27}$}

El último aspecto de la consideración del objeto como unidad de sentido que elucidaremos aquí es la manera de concebir el vínculo entre los objetos y sus propiedades. Esta problemática nos conducirá también al análisis del juicio predicativo ( $\mathrm{S}$ es $\mathrm{P}$ ), en el cual se expresa dicho vínculo.

Husserl no habla por lo general de "propiedades" ni de "atributos" de un objeto, sino más bien de "determinaciones" (Bestimmungen). Esta decisión terminológica da cuenta de un intento de alejarse de la visión que establece aquí distintos tipos de realidad, esto es, la realidad independiente de la sustancia y la realidad dependiente del atributo. Tampoco se habla de las propiedades como si fueran existencias de una índole particular, las cuales se vinculan esencialmente a ciertos objetos, de manera tal que se pueda decir que pertenecen a los mismos. Tales interpretaciones metafísicas acaban haciendo de estos vínculos un absoluto misterio.

Son conocidas las críticas que David Hume dirigió al enfoque sustancialista. En efecto, si nunca tenemos noticia de una sustancia desprovista de atributos, sino que siempre son éstos los que nos abren la consideración de aquélla, ¿cómo podemos estar seguros de que las sustancias existen como algo independiente? Podríamos decir incluso que no existen más que los atributos, pero esto también resulta problemático, ya que nos resulta imposible pensar el

27. Husserl se ha ocupado del vínculo entre el objeto y sus propiedades, así como de la manera en que dicho vínculo se expresa en enunciados de distinto tipo ( $\mathrm{S}$ es $\mathrm{P}, \mathrm{A}>\mathrm{B}$ ), en numerosas oportunidades: en los capítulos 6 y 7 de la Sexta Investigación Lógica, en los capítulos 5 y 6 de Ding und Raum y, con mayor grado de profundidad y detalle, en Erfahrung und Urteil (Experiencia y Juicio). 
atributo sin referirlo a una sustancia. El abordaje sustancialista, por lo tanto, termina conduciéndonos a todo tipo de enredos y confusiones. ${ }^{28}$

Husserl no habla de propiedades ni de atributos, sino de determinaciones. Con esto, sitúa la discusión no en el plano de la distinción metafísica entre tipos de realidad, sino en el plano de la indagación sucesiva de algo dado a la experiencia. La distinción entre el objeto y la propiedad no involucra realidades ni tipos de realidad dependientes o independientes, sino que es una distinción categorial que surge como resultado de un proceso de determinación. El vínculo entre ambos elementos, por otra parte, también se explica por la propia lógica de la indagación empírica. Esto tiene importantes repercusiones en la concepción general del objeto, así como en las reflexiones sobre la naturaleza de las propiedades primarias y secundarias, sensibles y morales, esenciales y accidentales.

El objeto despojado de las determinaciones no es entonces una sustancia, sino más bien una $\mathrm{X}$ vacía que sirve como centro o soporte del sentido objetivo que guía la orientación de la conciencia al objeto. «Un objeto intencional idéntico puede darse de diversas maneras según diferentes determinaciones, y la totalidad de las determinaciones es un polo ideal que rige un proceso de infinito enriquecimiento. ${ }^{29}$

Hay, por tanto, una X indeterminada que sirve de centro unificador de las determinaciones que conforman el sentido objetivo, del mismo modo en que el sujeto de una proposición sirve de centro unificador de todos los predicados que le corresponden. La manera en que se nos dan estos fenómenos en la experiencia y en el conocimiento nos muestra que no es posible disociar realmente al objeto de sus determinaciones o al sujeto de sus predicados. Ambas categorías se disocian y se vuelven a unir constantemente, como resultado de los procesos de indagación.

El objeto en sí mismo, sin determinaciones, es inconcebible. La consideración del objeto se nos abre siempre a partir de tal o cual determinación. De modo análogo, cualquier sujeto gramatical -incluyendo los nombres propios- cumple su función en la medida en que involucra -de modo más o menos explícito- un criterio de identidad en base a ciertos predicados. Por otro lado, tanto las determinaciones de las cosas como los predicados de los sujetos resultan impensables como realidades aisladas, se dan siempre en relación con una referencia unificadora.

Ahora bien, todo darse un objeto comprende siempre la co-evocación de su horizonte interno y de su horizonte externo. Con esto, lo que tenemos es que cada objeto implica dos direcciones de explicitación: la de sus propiedades (ej: $\mathrm{S}$ es $\mathrm{P}$ ) y la de sus relaciones (ej: A > B). La realidad del objeto es inconcebible 
sin la evocación de dichos horizontes de explicitación, del mismo modo que los horizontes son impensables sin un centro que los estructure y brinde el tema de la explicitación. Propiedades y relaciones son entonces categorías que surgen como resultado de los procesos de explicitación de los horizontes interno y externo. Lo mismo puede decirse de la categoría misma de objeto.

«El "lugar de origen" de la distinción categorial básica entre el objeto que oficia de sustrato y sus determinaciones se encuentra en el proceso de la consideración explicitante o simplemente explicitación.» ${ }^{30}$

La indagación del objeto es entonces un proceso que va de la consideración del mismo como un todo a una serie de consideraciones parciales, las cuales refieren nuevamente a la unidad del objeto. La indagación exige y presupone que lo indagado se mantiene uno e idéntico en la multiplicidad de aprehensiones parciales. Si no pudiéramos referir las determinaciones a un sustrato, no podríamos seguir el hilo de la explicitación, no podríamos saber si avanzamos en un mismo sentido ni tampoco si avanzamos en forma coherente. En este proceso el tema se constituye como "sustrato" y las parcialidades reveladas como "determinaciones" de dicho sustrato. Este movimiento que va del sustrato a la determinación y viceversa conduce a un sucesivo enriquecimiento del "sentido objetivo" de aquello que se indaga, al mismo tiempo que sirve de base a la síntesis predicativa.

La transición del objeto $S$ al momento $p$ en la síntesis explicitante tenía como resultado, junto a la constitución de $S$ como sustrato y de $p$ como determinación, el enriquecimiento del sentido objetivo del "objeto-sustrato" $S$, conservado, como tal, en su vigencia, en una modalidad peculiar del "mantener todavía asido". Sobre esta base, la síntesis predicativa toma ahora, en un primer paso, la forma de un "retroceso" hacia el objeto, en el cual se identifica al objeto nuevamente tan sólo como $S$, es decir, como nuevamente despojado o separado del momento $p$, unido sintéticamente a él, a través de la síntesis explicitante. ${ }^{31}$

El juicio predicativo no es una simple repetición de aquello dado en la aprehensión, sino que implica una síntesis activa que identifica parcialmente el momento p con el sustrato S. En la síntesis predicativa el "determinarse como p" de S es temáticamente aprehendido y se vuelve explícito bajo la forma "S es p". Esto implica una suerte de reiteración de la indagación inicial, pero ahora de carácter activo. La cópula "es" expresa la forma categorial propia de esta síntesis entre el objeto y la determinación, que no es por eso una simple repetición de la aprehensión, sino que implica una nueva categorización y la

30. Alejandro Vigo, Juicio, experiencia, verdad, EUNSA, Navarra, 2013, capítulo IV.

31. Ibídem, capítulo IV. 
consiguiente constitución de los "estados de cosas" como correlatos objetivos de los juicios predicativos.

\section{Conclusiones}

Quisiéramos destacar dos puntos de gran relevancia, en los cuales la visión husserliana, tal y como ha sido expuesta en este trabajo, se diferencia de los abordajes clásicos heredados de la modernidad: 1) En primer lugar, la consideración del darse de los objetos (en la percepción, en el conocimiento) como fenómeno dinámico y de carácter no atomista. 2) En segundo lugar, la consideración del objeto desde una perspectiva no sustancialista y no metafísica. Nuestro objetivo ha sido mostrar los vínculos entre estos dos puntos y la manera en que ambos se manifiestan en distintos aspectos del pensamiento de Husserl.

El primer punto ha sido trabajado más expresamente en los primeros apartados, relativos a la aprehensión (Auffassung) y los contenidos de sensación, así como también en los subsiguientes, que tratan sobre el rol esencial del movimiento y del entorno en la percepción de objetos, y sobre la dirección de interés como determinante del conocimiento. El segundo punto corresponde más a los apartados finales del trabajo, relativos a la manera de concebir, por un lado, la identidad y trascendencia del objeto, y por otro lado, el vínculo objeto-propiedad. La relación entre un punto y el otro -que resulta de gran importancia para entender por qué hemos tenido que incluir en este trabajo el análisis del primero de ellos- viene de la mano del hecho de que Husserl se sirve del modo de darse (Gegebenheitsweise) como punto de partida para sus estudios sobre el objeto.

Los abordajes aquí reconstruidos han servido de fundamento para la crítica de ciertas concepciones heredadas de la modernidad. De hecho, la manera husserliana de entender el objeto permite una comprensión de la distinción entre propiedades esenciales y accidentales que difiere significativamente de las visiones metafísico-sustancialistas. También permite discutir la idea de que ciertas propiedades se encuentran verdaderamente en el objeto, mientras que otras son puestas en él por el sujeto. Mucho menos podemos decir que para todo X haya un conjunto de propiedades esenciales que definen su identidad de modo absoluto. Todas estas categorías se definen en un proceso de indagación.

Para Husserl, el conocimiento no implica la determinación absoluta de una realidad "en sí", sino que más bien se compone de un conjunto de respuestas válidas a preguntas surgidas en la experiencia y dirigidas a la experiencia. La indagación no crea objetos y propiedades arbitrariamente: delimita lo esencial y lo inesencial, al mismo tiempo que establece un tema alrededor del cual se organizan las consideraciones. Cada aspecto develado no es una "propiedad" cuya pertenencia al objeto o a la mente deba ser establecida a partir de un es- 
quema metafísico previo, sino que es una "determinación", una ampliación del sentido objetivo del objeto ganada en un proceso de indagación. Entendiendo las cosas de esta manera, hemos de decir que no hay determinaciones en la mente, todas son concebidas como determinando al objeto, como definiendo aquello que el objeto es. ${ }^{32}$

Para terminar, diremos que el equilibrio buscado por Husserl es, como se habrá advertido, delicado y complejo. En líneas generales, podríamos decir que intenta alejarse de la visión realista -que desconoce la importancia de los procesos de aprehensión- sin caer en una destrucción idealista de cualquier noción de objetividad. Esta dirección es probablemente la más difícil de transitar para cualquier filosofía, pero nos parece también la más acertada. Lo contrario sería simplemente pensar que el conocimiento se da en una especie de contacto inmediato con el objeto y que consiste en la obtención de una imagen rígida del mismo, o bien establecer las identidades en cada caso por definición, a la manera metafísica. Semejantes procedimientos se encuentran más cerca del pensamiento mágico que del razonamiento crítico. Por el contrario, Husserl sostiene que dirigirse a un objeto es en cada caso estar frente a un horizonte de indagación, lo que significa que no pueden sacarse conclusiones absolutas a partir de un elemento aislado.

32. Es claro que la ampliación de la noción de objeto más allá de ciertas determinaciones privilegiadas (primarias, visuales) llevada a cabo por Heidegger y por la hermenéutica se fundamenta en estas consideraciones husserlianas y es impensable sin ellas. 
